\title{
Study of the Working Postures of Nurses and Laboratory Technicians by Modified REBA Method at a Hospital in Tabriz
}

\author{
Fatemeh Farrokhi ${ }^{1}$, Abolfazl Ghahramani ${ }^{2}$, Samira Orujlu ${ }^{3}$, Mohammad Hajaghazadeh,"* \\ ${ }^{1}$ MS student of Ergonomics, Health faculty, Urmia University of Medical Sciences, Urmia, Iran \\ 2 Assistant professor, Department of Occupational health, health faculty, Urmia University of Medical Sciences, Urmia, Iran \\ ${ }^{3}$ PhD student of nursing, Nursing \& Midwifery School, Tabriz University of Medical Sciences, Tabriz, Iran \\ ${ }^{4}$ Associate professor, Department of Occupational health, health faculty, Urmia University of Medical Sciences, Urmia, Iran
}

* Corresponding Author: Mohammad Hajaghazadeh, Department of Occupational health, health faculty, Urmia University of Medical Sciences, Urmia, Iran. Email: hajaghazadeh@gmail.com

Received: $24 / 08 / 2018$

Accepted: 13/12/2018

\section{How to Cite this Article:}

Farrokhi F, Ghahramani A, Orujlu S, Hajaghazadeh $M$. Study of the Working Postures of Nurses and Laboratory Technicians by Modified REBA Method at a Hospital in Tabriz. J Occup Hyg Eng. 2018; 5(3): 35-44. DOI: 10.21859/johe. 5.3 .35

\section{Abstract}

Background and Objective: The work conditions of nurses and laboratory technicians can lead to musculoskeletal disorders. The aim of the present study was to examine the working conditions of nurses in internal and surgical wards and laboratory technicians in a hospital.

Materials and Methods: This was a descriptive cross-sectional study which was conducted in a hospital in Tabriz in 2016. Thirty-two nurses and 20 laboratory technicians were participated in the study. The Nordic questionnaire and REBA method with a new scoring algorithm were used for ergonomic evaluation. For each occupation, the scores of upper body, upper quadrant, lower body, and the percentage of work-time spent with high-strain postures were calculated. One-way ANOVA and independent $t$ tests were used for statistical analysis.

Results: The musculoskeletal disorders in neck (63.5\%) and waist (55.8\%) were prevalent. The mean scores of upper body, upper quadrant, and lower body were $8.16,11.01$, and 9.59, respectively. Only the score of lower body was statistically different among three occupational groups due to the difference in the score of the lower body of technicians with nurses. Internal nurses in $11 \%$ of and laboratory technicians in $8 \%$ of their work shift worked with high-strain postures of upper and lower body, respectively.

Conclusion: The REBA method was easily accomplished in the workplace of nurses and laboratory technicians. The internal nurses experience more biomechanical stress than general surgery nurses, especially in upper body. To reduce the high strain postures, the implementation of ergonomic interventions are recommended to improve the postures of upper body of nurses and lower body of laboratory technicians.

Keywords: Ergonomics; Laboratory Technicians; Musculoskeletal Disorders; Nurses; REBA 
doi): $10.21859 /$ johe.5.3.35

مطالعه يوسجر هاى كارى برستاران و تكنسينهاى آزمايشكاه با استفاده از روش REBA تعديلشده در بيمارستانى در شهر تبريز

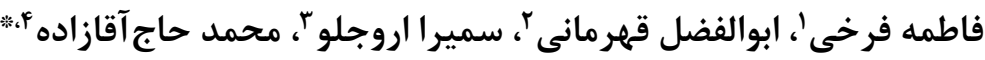
' دانشجوى كارشناسى ارشد ار گَونومى، دانشكده بهداشت، دانشكاه علوم يزشكى اروميه، اروميه، ايران

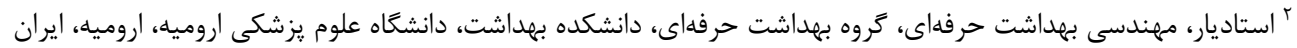

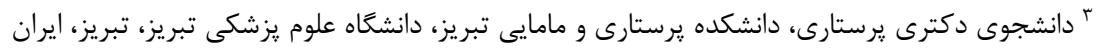

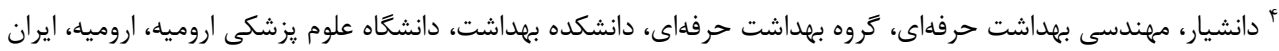
* نويسنده مسئول: محمد حاجآقازاده، مهندسى بهداشت حرفهاى، گروه بهداشت حرفهاى، دانشكده بهداشت، دانشكاه علوم يزشكى اروميه، اروميه، ايران. ايميل: hajaghazadeh@gmail.com

\section{جكيده}

سابقه و هدف: شرايط كار يرستاران و تكنسينهاى آزمايشكاه مىتواند منجر به ايجاد اختلالات اسكلتى - عاضل

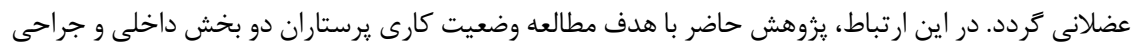

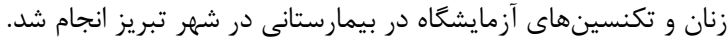

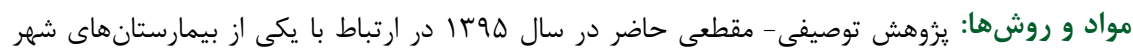

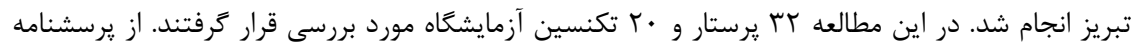

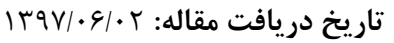
تاريخ يذيرش مقاله:

تمامى حقوق نشر براى دانشعاه علوم يزشكى همدان محفوظ است.

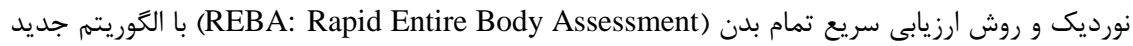

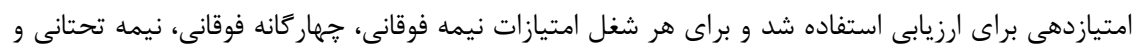

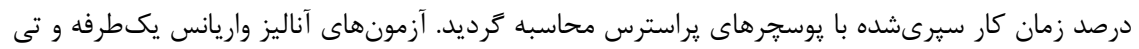

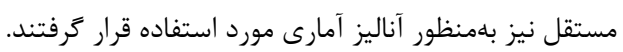

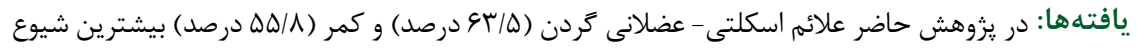

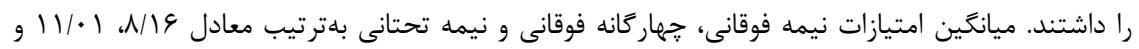

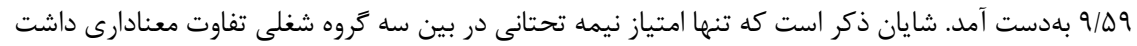

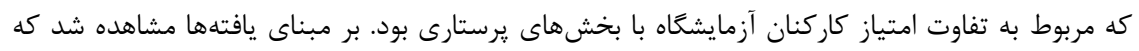

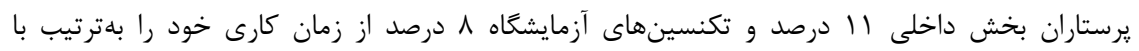

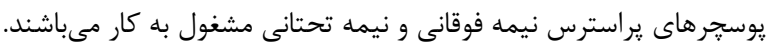

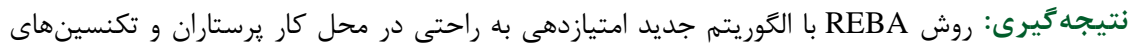

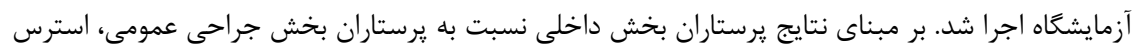

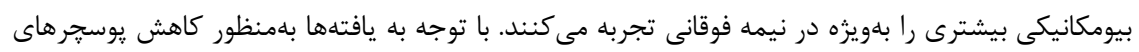

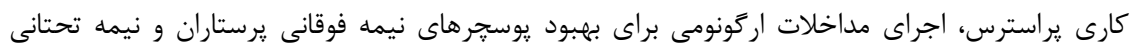

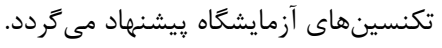

وازَّان كليدى: اختلالات اسكلتى- عضلانى؛ ارَّونومى؛ يرستاران؛ تكنسينهاى آزمايشكاه؛ REBA

\begin{abstract}
اختلالات اسكلتى - عضلانى ناشى از كار قرار دارند [1]]. اين اختلالات بهعنوان يك بيامد يرهزينه شغلى در ارتباط بات بات كاركنان

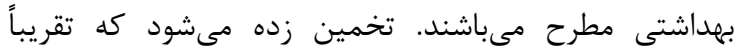

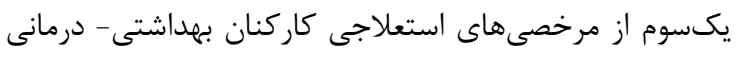

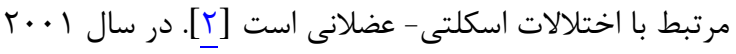

مقلدمه در بيمارستانها طيف گستردهاى از كاركنان ارائهدهنده خدمات درمانى وجود دارد كه شامل: كاركنان كلينيكى (مانند

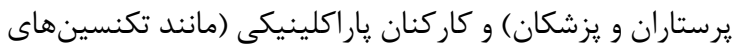

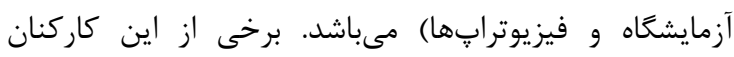

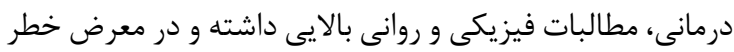




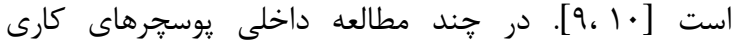

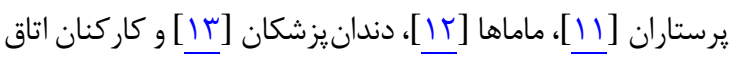

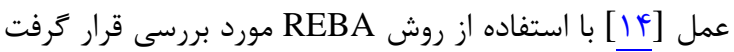

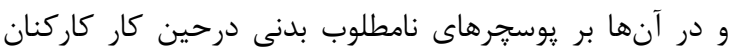

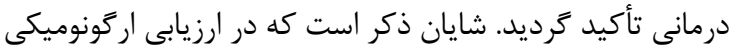

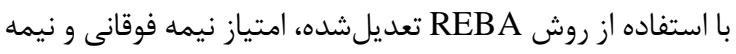
تحتانى بدن بلهور جداكانه محاسبه مىشود [1]

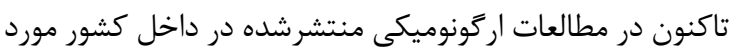

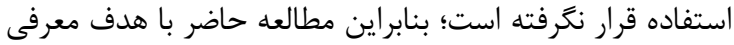

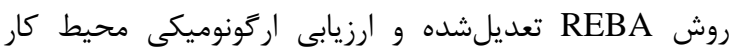

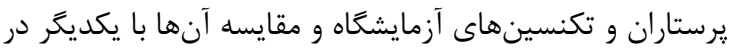
بيمارستانى در شهر تبريز انجام شد.

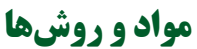

مطالعه توصيفى حاضر در سال هوبا در ارتباط با يكى از بيمارستانهاى شهر تبريز انجام شد. جامعه هدف، برستاران و دار

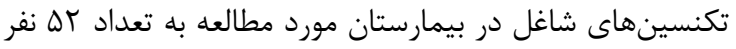

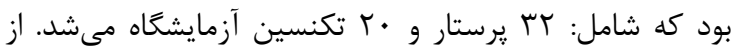

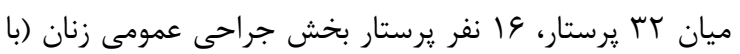

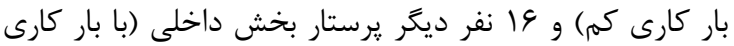

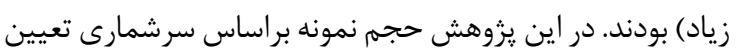
شد و كليه يرستاران دو بخش مربوطه و تكنسينهاى آز آزمايشكاه

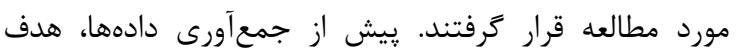
يزوهش و روش كار به افراد شركت كننده در مطالعه توضيح داده

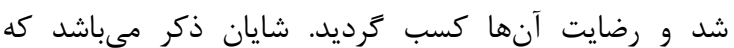
ملاحظات اخلاقى يزوهش حاضر توسط كميته اخلاق دانشكاه علوم يزشكى اروميه با كد

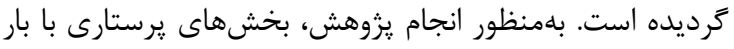

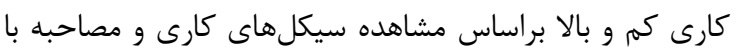

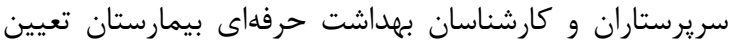

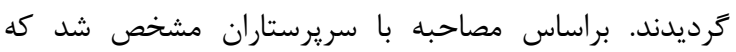

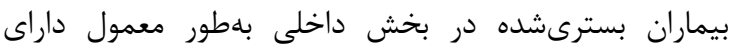

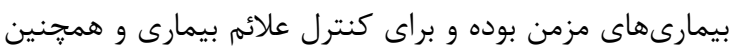

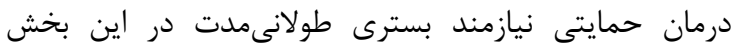

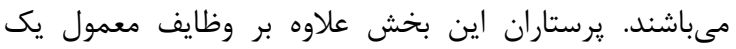

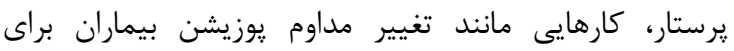
جلوكيرى از زخم بستر، حمام كردن بيمار در تخت، ساكشن كردن

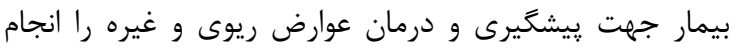

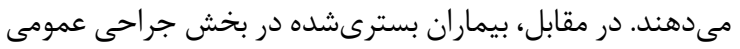

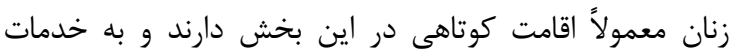

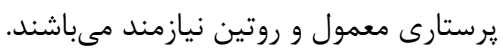

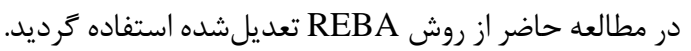

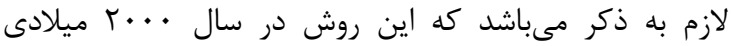
بلمنظور ارزيابى اركَونوميكى مشاغل بهداشتى - درمانى ارائه
در ايالات متحده آمريكا، بيمارستانها از نظر تعداد آسيبها و

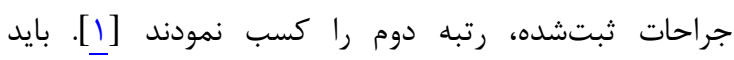
خاطرنشان ساخت كه شيوع اختلالات اسكلتى - عضلانى در ميان

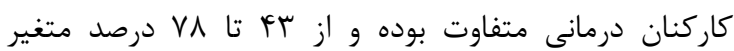
مىباشد. اين آمار در كشورهاى مختلف، متفاوت كزارش شار شده

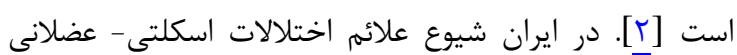

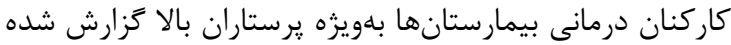

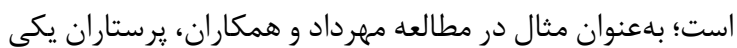

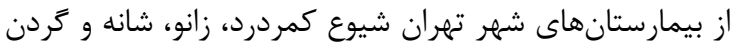

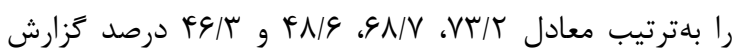

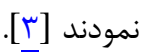
در مطالعات اركونوميكى صورتكرفته در ارتباط با مشاغل بيمارستانى، شغل يرستارى بيشتر مورد مطالعه قرار كرفته و ورئه

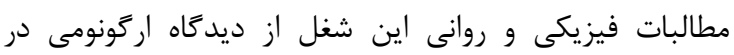

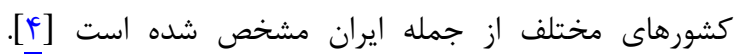

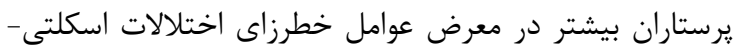

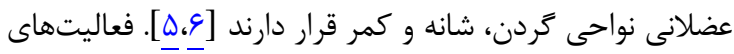

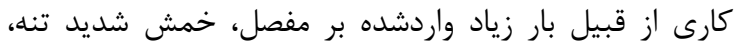

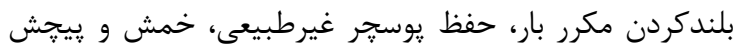

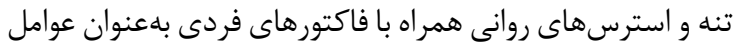

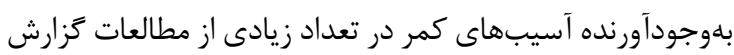

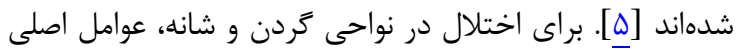

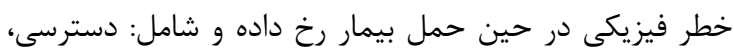

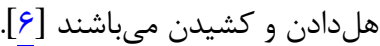

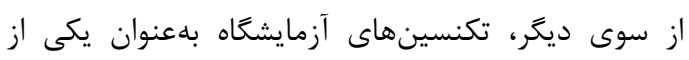

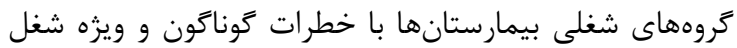
خود مواجه هستند و عوامل اركَونوميكى محيط كار آنهات كآنا

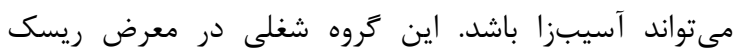

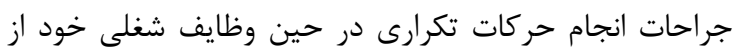

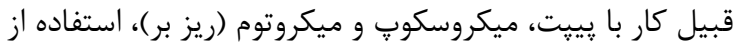

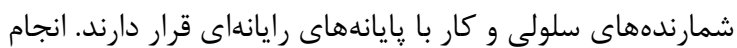

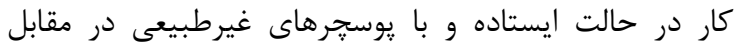

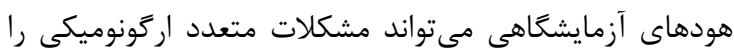

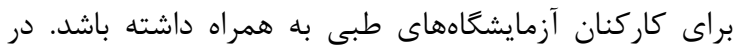

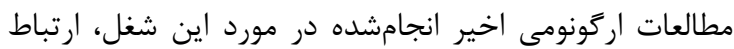

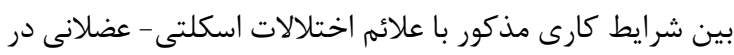

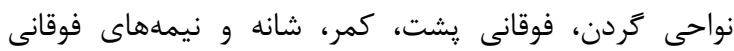

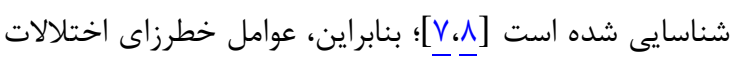

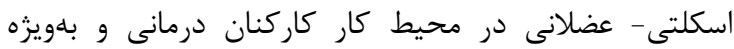

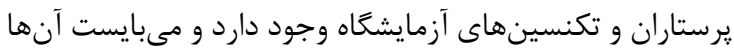

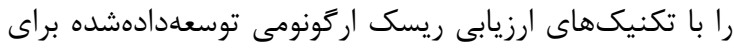
محيطهاى درمانى ارزيابى كرد. در كشور ايران شيوع اختلالات اسكلتى - عضلانى در ميان

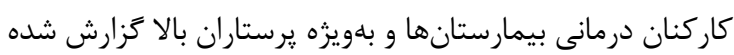


امتيازدهى با جزئيات در يزوهش Janowitz و همكاران ارائه شده

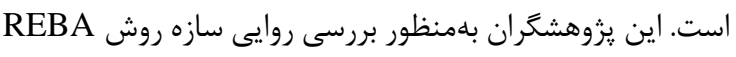

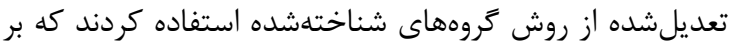

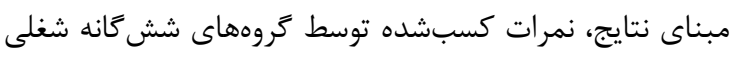

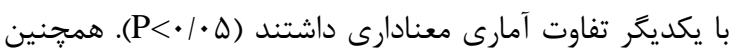

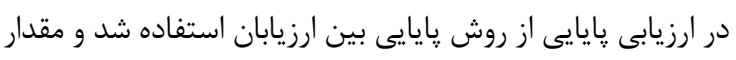

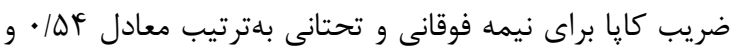

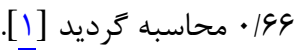

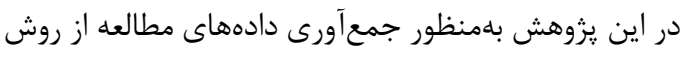

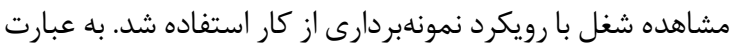

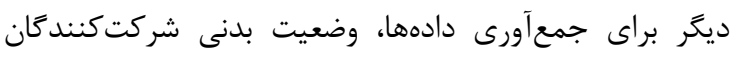

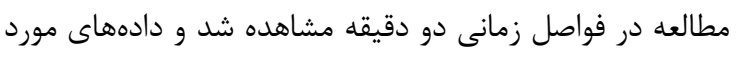

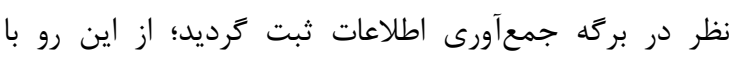

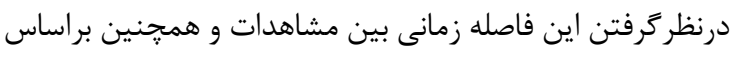

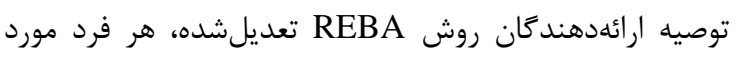

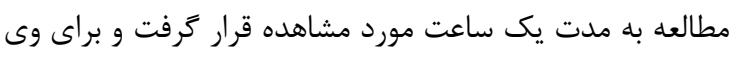

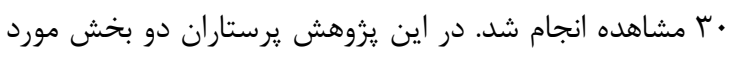

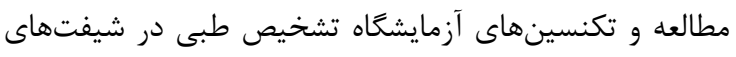

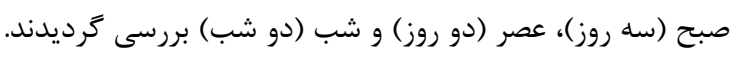

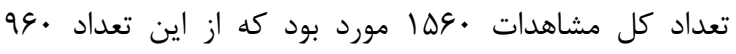

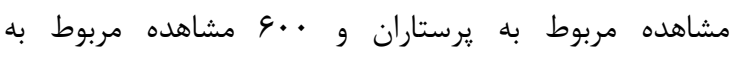

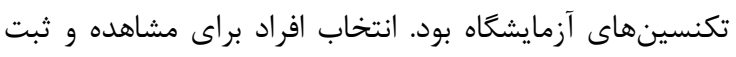
اطلاعات بهصورت تصادفى انجام شد.

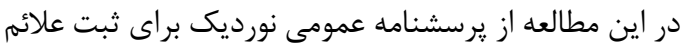

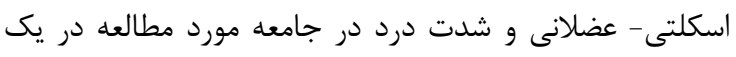

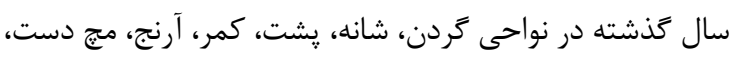

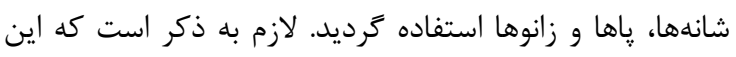

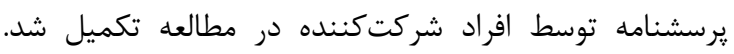

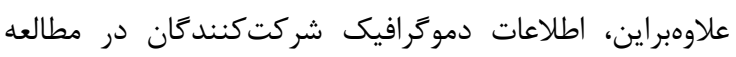

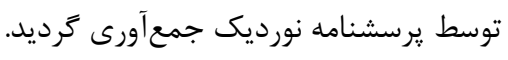

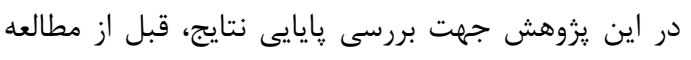

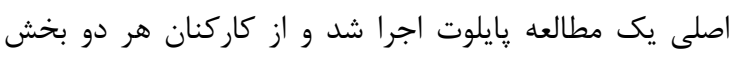

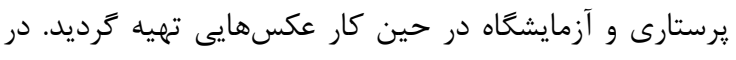

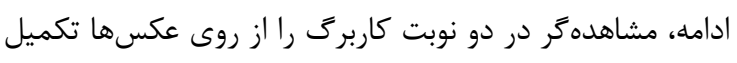

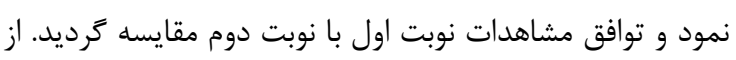

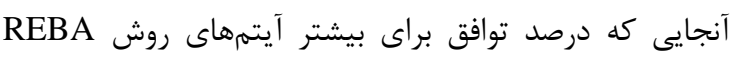

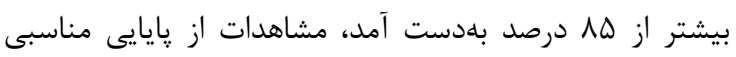

كرديده و براى مشاغلى مانند يرستاران شاغل در بيمارستان و

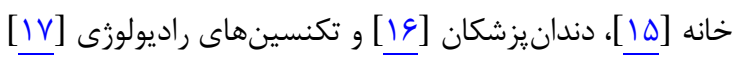

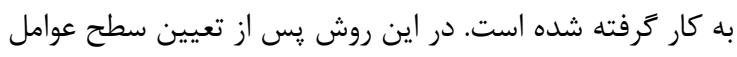

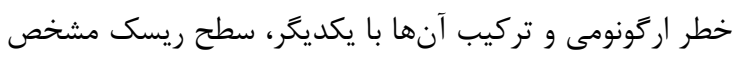

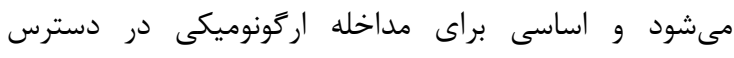

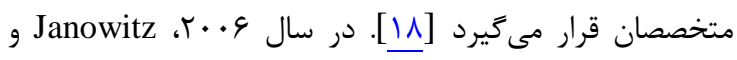

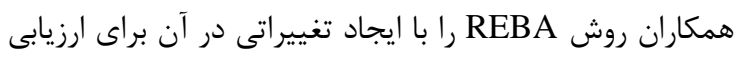

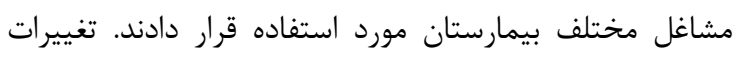

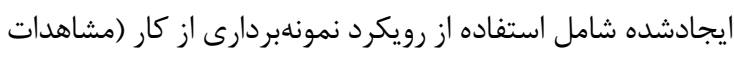

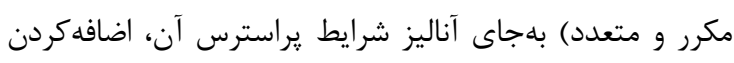

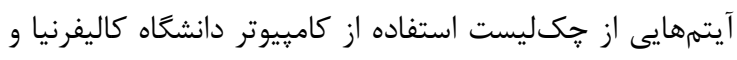

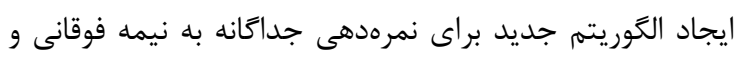

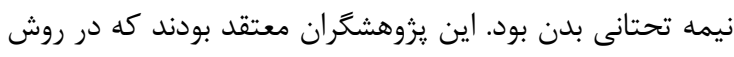

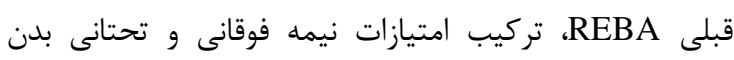

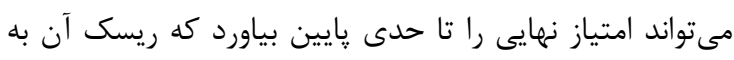

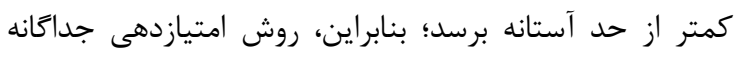

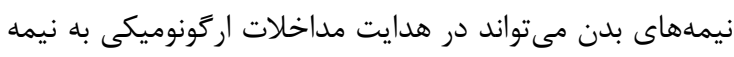

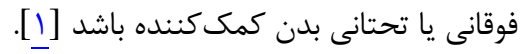

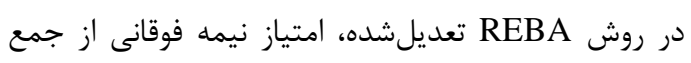

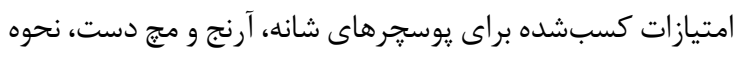

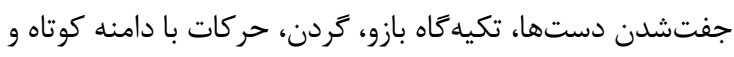

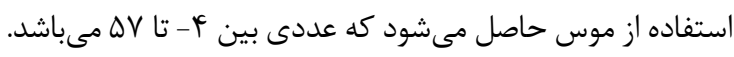

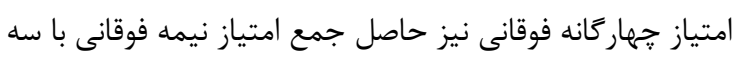

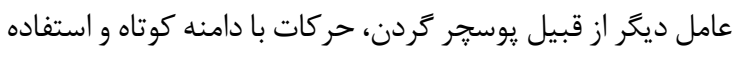

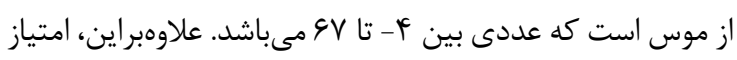

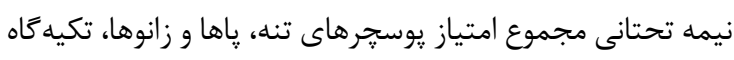

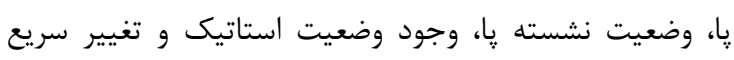

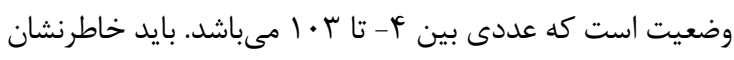

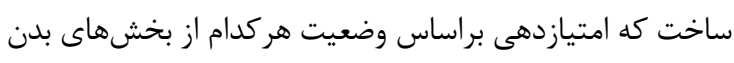

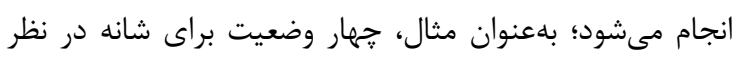

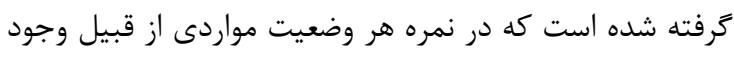

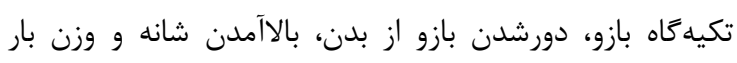

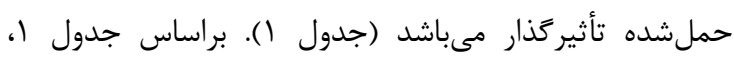

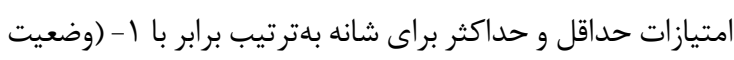

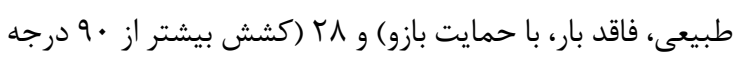

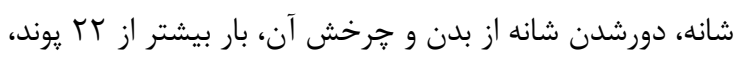

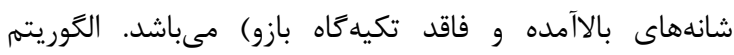

جدول ا: يوسجرهاى شانه و امتيازدهى آنها

\begin{tabular}{|c|c|c|c|}
\hline افزايش امتياز & حمايت بازو & امتياز & وضعيت \\
\hline - قبل از محاسبه اثر بار، دو امتياز براى حركت دورشدن از محور & -1 & • & كشش كمتر از •r درجه يا خمش •r- • درجه \\
\hline 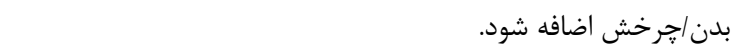 & $-t$ & r & خمش \\
\hline 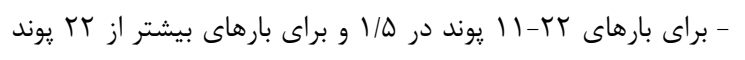 & r & f & كشش بيشتر از •r درجه يا خمش •و-qu درجه \\
\hline - در صر ضرب شورت بالآددن شانه، 1 امتياز اضافه كَردد. & $-\Delta$ & $\checkmark$ & خمش بيشتر از •9 درجه \\
\hline
\end{tabular}


عضلانى در نواحى مختلف بدن افراد مورد مطالعه طى يك سال

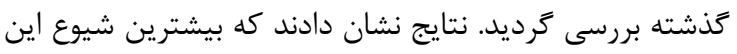

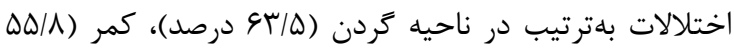
درصد)، يشت (

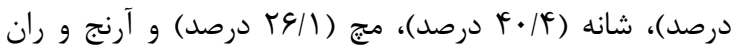

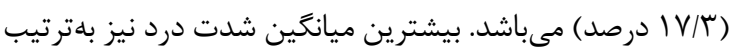

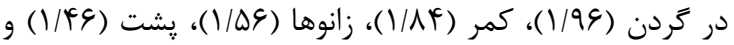

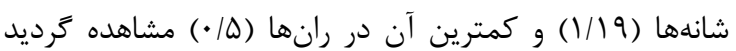

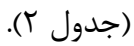

در بررسى نتايج روش REBA، امتياز قسمتهاى مختلف

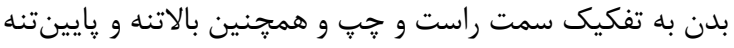

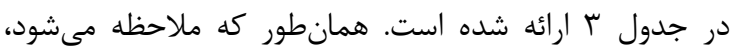
ميانگين امتياز نيمه فوقانى، جهاركانه فوقانى و نيمه تحتانى

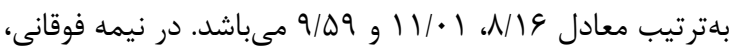

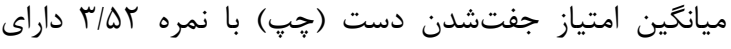

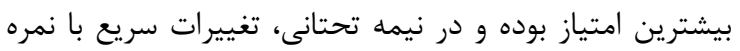

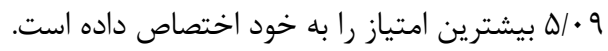

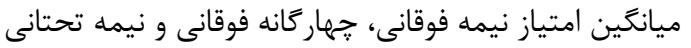

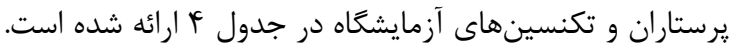
همانطور كه ملاحظه مىشود، تنها ميانگين امتياز نيمه تحتانى

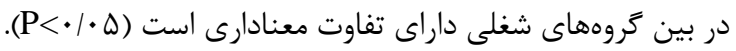

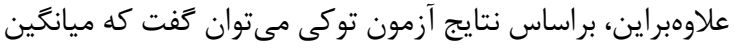

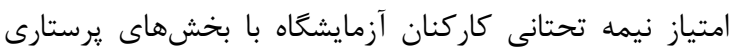

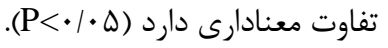

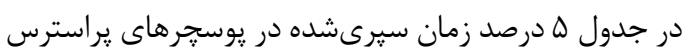

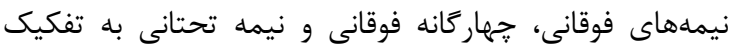

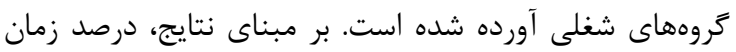

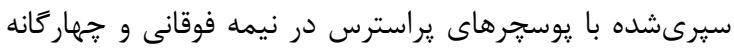

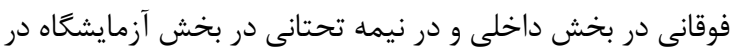

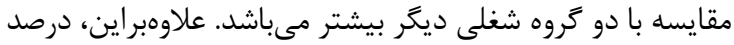

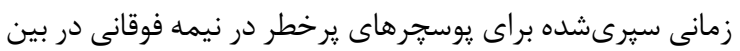

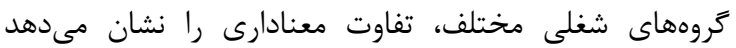

برخوردار بودند.

بهمنظور تجزيه و تحليل دادهها از نرمافزار 16 SPSS استفاده

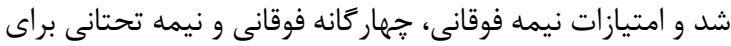

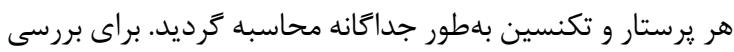

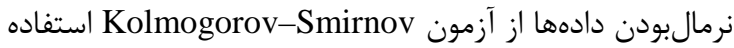
شد و مشخص كرديد كه امتيازات نيمه فوقانى و تحتانى بدن از از

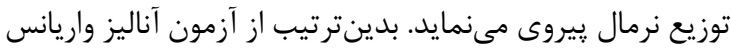
يكىطرفه براى مقايسه امتيازات نيمه فوقانى، جهار كانه فوقانى

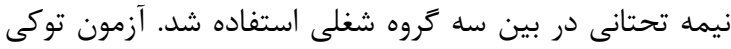

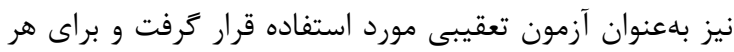

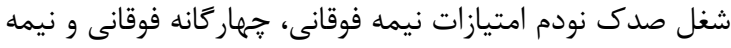

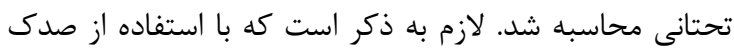

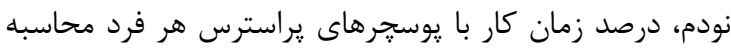

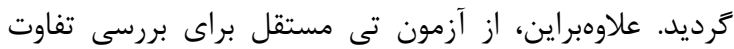

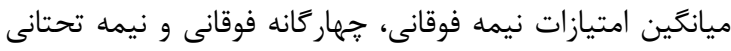

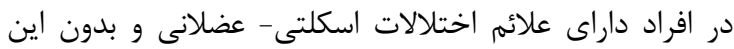

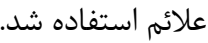

\section{كافته ها}

در اين يزوهش اطلاعات دموكرافيك افراد مورد مطالعه به

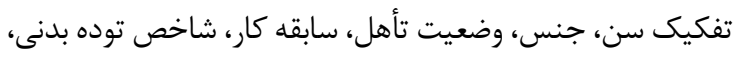

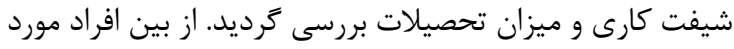

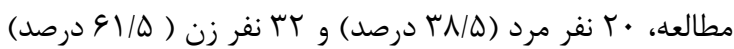

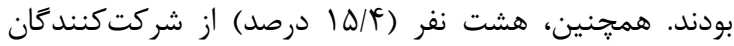

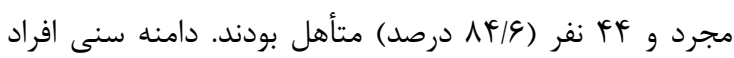

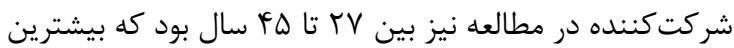

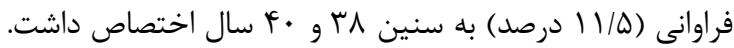

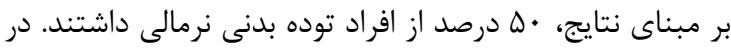

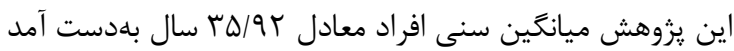

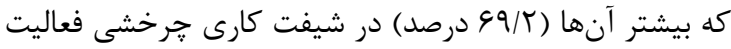
داشتند. جهت انجام يزوهش، ميزان شيوع اختلالات اسكلتى-

\begin{tabular}{|c|c|c|c|}
\hline \multirow{2}{*}{ ميانغين شدت درد } & \multicolumn{2}{|c|}{ شيوع اختلالات اسكلتى - عضلانى } & \multirow{2}{*}{ ناحيه اختلال } \\
\hline & درصد & 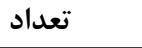 & \\
\hline 1/99 & $s \mu / \Delta$ & rr & 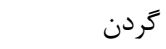 \\
\hline $1 / 19$ & $r \cdot / f$ & 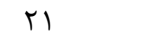 & شانهها \\
\hline $1 / 49$ & $01 / 9$ & tr & يشت \\
\hline$\cdot \mid \Delta K$ & $I V / r$ & 9 & آرنجها \\
\hline$\cdot / \wedge 9$ & $r \& / 9$ & If & مج و دستها \\
\hline l/AF & $\Delta \Delta / \Lambda$ & rq & 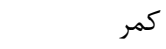 \\
\hline$\cdot 10$ & $I V / r$ & 9 & رانها \\
\hline $1 / 01$ & $\uparrow \& / T$ & TF & 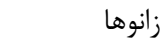 \\
\hline $1 / \Delta \Delta$ & YN/I & ra & ياها \\
\hline
\end{tabular}


جدول با: مقايسه ميانخين، صدك • 9 و دامنه مشاهدات براى قسمتهاى مختلف بدن در كل جامعه

\begin{tabular}{|c|c|c|c|c|c|}
\hline دامنه ممكن & دامنه مشاهدهشده & صدك نود & ميانگين & & آيتمها \\
\hline r & r & r & $1 / 1 r$ & راست & \multirow{2}{*}{ يوسجر شانه } \\
\hline r & 1. & f & $.19 r$ & جֶ & \\
\hline • تا F & • تا & r & $\cdot / 199$ & راست & \multirow{2}{*}{ يوسجر آرنج } \\
\hline • تأ & • تأ & $r$ & $\cdot$ /VG & جֶ & \\
\hline 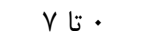 & 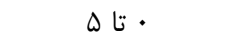 & r & $\cdot 19$ & راست & \multirow{2}{*}{ يوسجر مج دست } \\
\hline 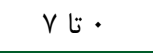 & 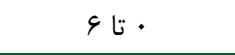 & r & $1 / \cdot f$ & جֶ & \\
\hline V ت & 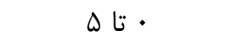 & $\Delta$ & $T / T \Lambda$ & 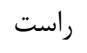 & \multirow{2}{*}{ جفتشدن دست } \\
\hline 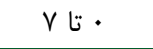 & 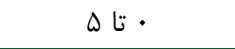 & $\Delta$ & $r / \Delta r$ & جֶ & \\
\hline r- تا r & r- تا س & $\cdot$ & $-\cdot / 11$ & راست & \multirow{2}{*}{ تكيه كاه بازو } \\
\hline r- تا س & r- تا r & $\cdot$ & $-\cdot \cdot \cdot \Delta$ & ج" & \\
\hline$\Delta V$ ت & rا & 11 & $1 / 19$ & & امتياز نيمه فوقانى \\
\hline • ت ا ل & • ت • & $\Delta$ & $1 / K 1$ & & يوسجر گردن \\
\hline 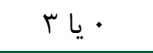 & • & r & $1 / r V$ & & حركات با دامنه كوتاه \\
\hline · ت · · & · ت & • & $\cdot 1 \cdot 1$ & & استفاده از موس \\
\hline GV ت F & r & IV & $11 / \cdot 1$ & & امتياز جهار گانه فوقانى \\
\hline VY ت F & 1 & 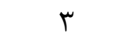 & $1 / 19$ & & يوسجر تنه \\
\hline r- تا س & r & 1 & $\cdot \mid T_{1}$ & 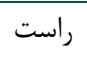 & \multirow{2}{*}{ يوسجر يا } \\
\hline r- & | & 1 & $\cdot|K|$ & קֶ" & \\
\hline 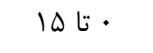 & 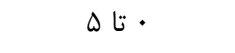 & $\cdot$ & 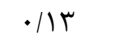 & 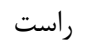 & \multirow{2}{*}{ يوسجر زانو } \\
\hline • • & · • ت ل & $\cdot$ & $\cdot / 1 \cdot$ & קֶ" & \\
\hline 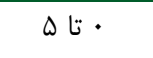 & • تا ه & r &.$/ 49$ & 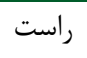 & \multirow{2}{*}{ حمايت ڤا } \\
\hline • تا ه & • ت ت ه ه & r & $\cdot|\Delta|$ & ج" & \\
\hline • تا r & • ت · r & 1 & $\cdot / T 9$ & راست & \multirow{2}{*}{ وضعيت يا در حالت نشسته } \\
\hline · · · · & • ت · r & 1 & $\cdot / 4 \Lambda$ & جֶ & \\
\hline · · ل & · · ل & $\Delta$ & $1 / 79$ & & وضعيت استاتيك \\
\hline 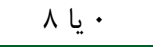 & ᄉ & $\Lambda$ & $\Delta / \cdot 9$ & & تغييرات سريع \\
\hline 1. & r تا كץ & If & $9 / \Delta 9$ & & امتياز نيمه تحتانى \\
\hline
\end{tabular}

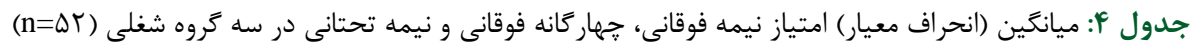

\begin{tabular}{|c|c|c|c|}
\hline نيمه تحتانى & جهار كانه فوقانى & نيمه فوقانى & كروه شغلى \\
\hline $1 \cdot / T T(1 / K F)$ & $1 \cdot / 90(1 / 49)$ & $N \cdot r(1 / \cdot r)$ & يرستاران بخش جراحى عمومى زنان \\
\hline $1 \cdot 1 \cdot V(\cdot / 91)$ & $11 / \cdot 9(\cdot / 99)$ & $\wedge / 1 \wedge(\cdot / \vee \Delta)$ & يرستاران بخش داخلى \\
\hline$\Lambda / V I(\cdot / 9 \Delta)$ & $1.199(1 / 99)$ & $N / T \&(\cdot / 9 \Delta)$ & تكنسينهاى آزمايشعاه \\
\hline $11 / \mathrm{V} \Lambda$ & $\cdot|4|$ & ( & Fقدار F F F F F F F F F \\
\hline$\cdot 1 \cdot 1$ & .199 & $\cdot / \mathrm{N}$ & سطح معنادارى \\
\hline
\end{tabular}

جدول ه: ميانكين (انحراف معيار) درصد زمان سيرىشده در يوسجرهاى يراسترس نيمه فوقانى، جهار گانه فوقانى و نيمه تحتانى در سه گروه شغلى (n=Dr)

\begin{tabular}{|c|c|c|c|}
\hline نيمه تحتانى & جهمار كَانه فوقانى & نيمه فوقانى & كروه شغلى \\
\hline$F / \Delta \wedge(F / 99)$ & $\operatorname{si\Lambda V(F/F\Delta )}$ & $F / T V(r / 9 \Lambda)$ & يرستاران بخش جراحى عمومى زنان \\
\hline$r / \Delta r(r / q \mu)$ & $N / 9 \Delta(9 / 94)$ & $1 \cdot / \Lambda r(V / \cdot F)$ & يرستاران بخش داخلى \\
\hline$\Lambda / \Gamma(V / 9)$ & $9 / 99(9 / V Y)$ & $\varepsilon / \wedge r(\varepsilon / r \Delta)$ & تكنسينهاى آزمايشعاه \\
\hline$r / l V$ & $\cdot / \cdot r$ & $\boldsymbol{\varphi} / \Lambda$ & مقدار F F \\
\hline$\cdot / \cdot \Delta$ & • & $\cdot / \cdot 1$ & سطح معنادارى" \\
\hline
\end{tabular}


استفاده از آزمون t مستقل به لحاظ آمارى بررسى گرديد.

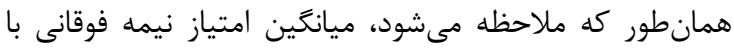

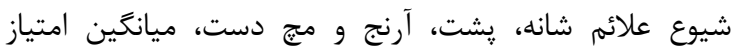

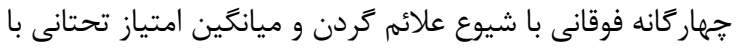

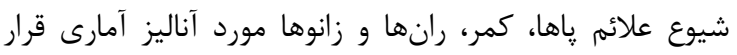

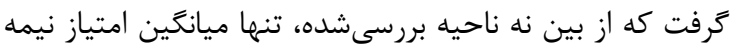

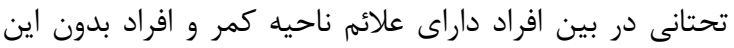

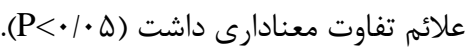

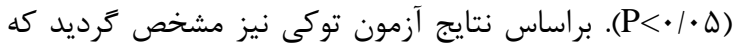

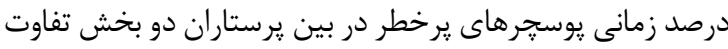

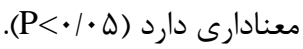

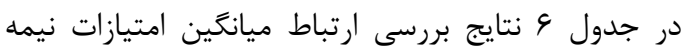

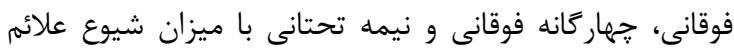

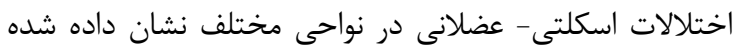

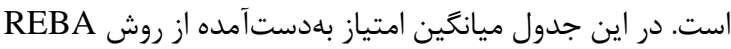

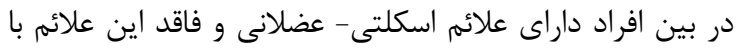

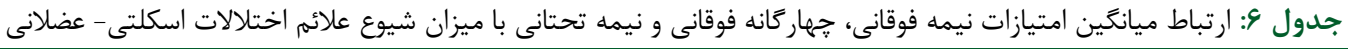

\begin{tabular}{|c|c|c|c|c|}
\hline نتايج آزمون t مستقل & عضلانى (انحراف معيار) ميانكين & عضلانى (انحراف معيار ) ميانكين & ناحيه & $\begin{array}{r}\text { اجزاى روش } \\
\text { REBA }\end{array}$ \\
\hline $\mathrm{P}=\cdot / T \mid, \mathrm{t}=-1 / T \mathcal{F}, \mathrm{df}=\Delta$. & $N / \cdot F(\cdot / 9)[r /]$ & $\Lambda / r \Delta(\cdot \mid \wedge q)[r \mid]$ & 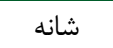 & \multirow{4}{*}{ 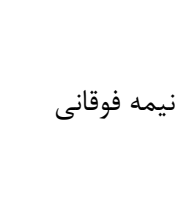 } \\
\hline $\mathrm{P}=\cdot / / 1, \mathrm{t}=1 /{ }^{-} 9, \mathrm{df}=\Delta$. & $\Lambda / r V(\cdot / 9 q)[r \Delta]$ & $V / Q V(1 / \cdot F)[Y V]$ & يشت & \\
\hline $\mathrm{P}=\cdot / 9 \varphi, \mathrm{t}=-\mathrm{r} / \mathrm{r} \mathrm{r}, \mathrm{df}=\omega \cdot$ & $N / / F(\cdot|\Lambda|)[F r]$ & $\wedge / r \wedge(1 / \cdot \nvdash)[q]$ & آرنج & \\
\hline $\mathrm{P}=\cdot / \wedge \vee, \mathrm{t}=\cdot / 19, \mathrm{df}=1 \wedge$ & $\Lambda / \wedge(\cdot / \Lambda))[\curlyvee \wedge]$ & $N / 1 K(\mid / / Q)[\mid Y]$ & مهج دست & \\
\hline $\mathrm{P}=\cdot \mid \Lambda \cdot, \mathrm{t}=\cdot / T \Delta F, \mathrm{df}=\omega \cdot$ & $11 / \cdot V(1 / 49)[19]$ & 1./9V (I/rی) [rr] & 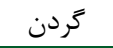 & جهار كانه فوقانى \\
\hline $\mathrm{P}=\cdot / \Gamma \Delta, \mathrm{t}=-\cdot / 9 \uparrow, \mathrm{df}=\Delta \cdot$ & $q / F F(1 / T \Lambda)[Y V]$ & $q / \vee \&(1 / / \Lambda)[r \Delta]$ & يا & \multirow{4}{*}{ نيمه تحتانى } \\
\hline $\mathrm{P}=\cdot / / \Delta, \mathrm{t}=-1 / \uparrow, \mathrm{df}=\omega$ & $9 / r r(1 / \cdot \Delta)[r r]$ & $q / \Lambda)(1 / r q)[r q]$ & 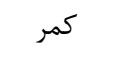 & \\
\hline $\mathrm{P}=\cdot|\Delta \cdot, \mathrm{t}=\cdot| \Delta \mathrm{V}, \mathrm{df}=\Delta \cdot$ & $9 / G F(1 / K \Lambda)[F T]$ & $9 / r V(1 / \cdot r)[q]$ & 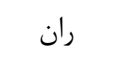 & \\
\hline$P=\cdot / \cdot r, t=-r / \cdot V, d f=\Delta \cdot$ & $q / r \vee(1 / r \Delta)[r \Lambda]$ & $9 / 9 \vee(1 / / r)[Y \Psi]$ & زانو & \\
\hline
\end{tabular}

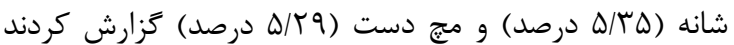

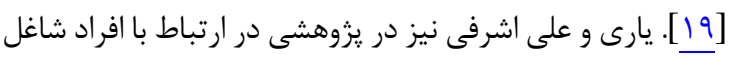

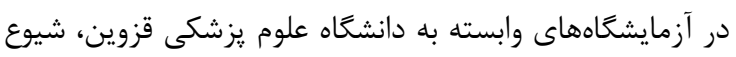

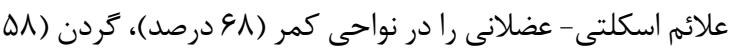

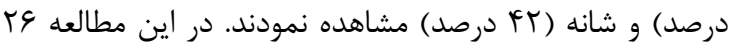

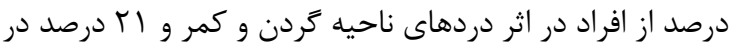

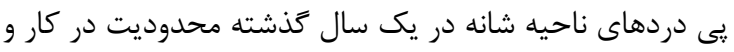

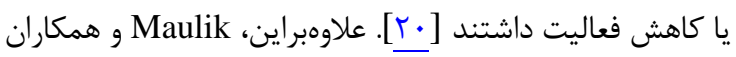

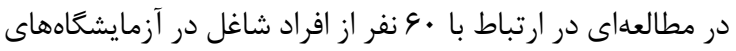

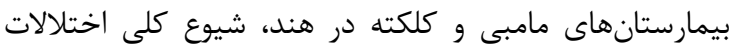

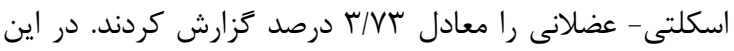

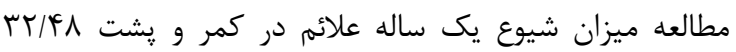

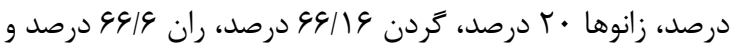

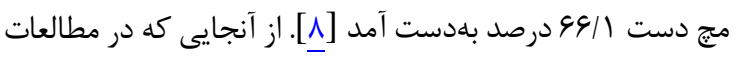

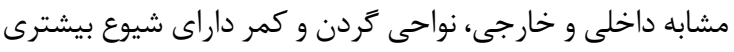

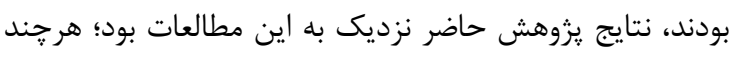

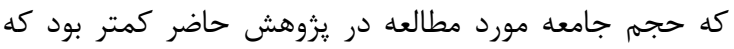

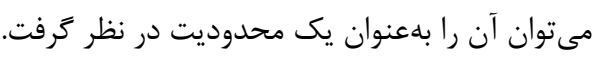

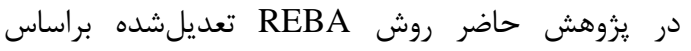
امتيازدهى جداكانه براى نيمههاى فوقانى و تحتانى مورد استفاده

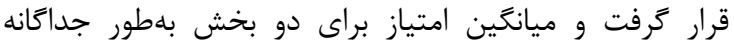

هدف از مطالعه حاضر تعيين شيوع اختلالات اسكلتىعضلانى و وضعيتهاى كارى يرستاران دو بخش داخلى و جراحى لئى

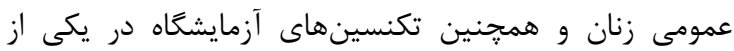

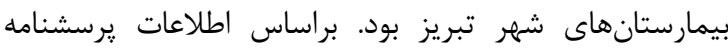

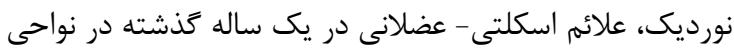

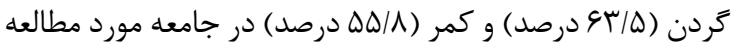

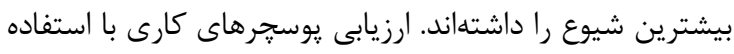
از روش REBA تعديلشده نيز نشان داد كه نيمه تحتانى دئي

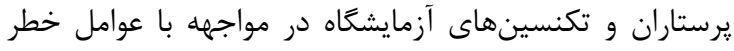

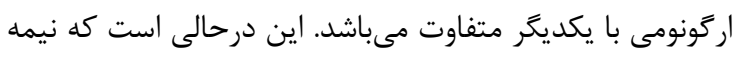

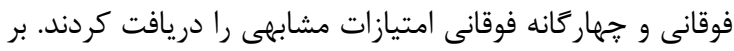

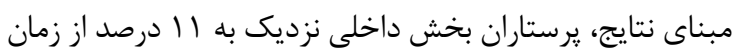

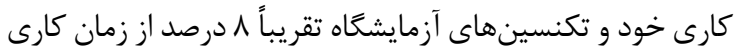

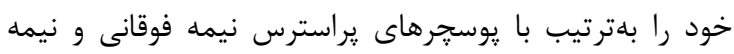
تحتانى مشغول به كار بودند.

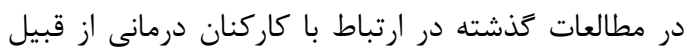

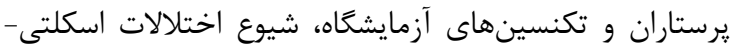

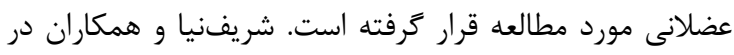

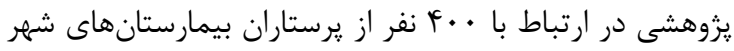

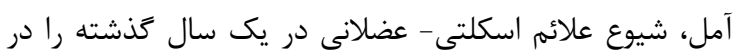

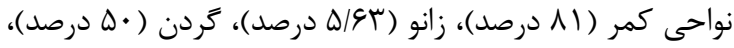


است كه درصد زمان سيرىشده در يوسجرهاى يرخطر در

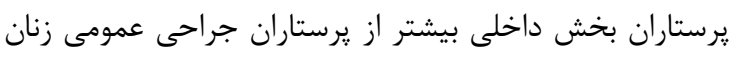

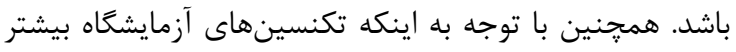

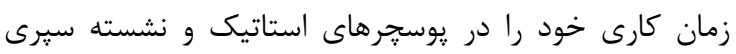

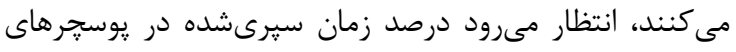

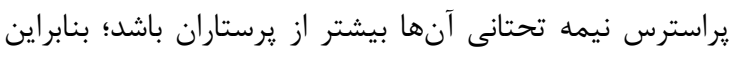

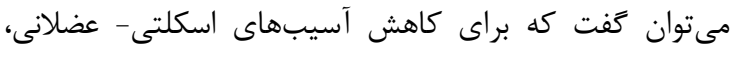

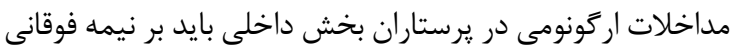

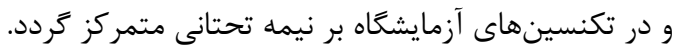

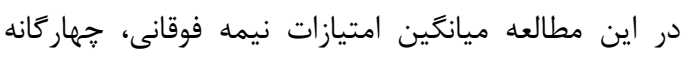

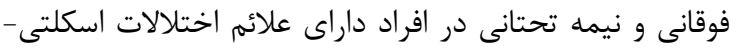

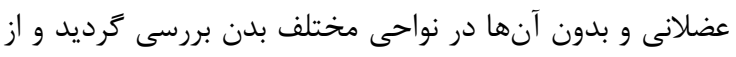

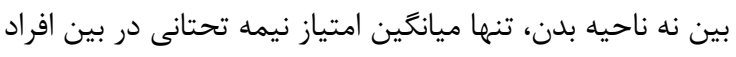

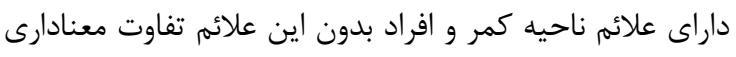

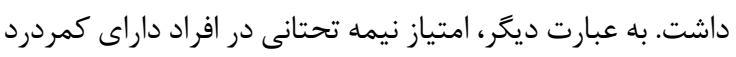

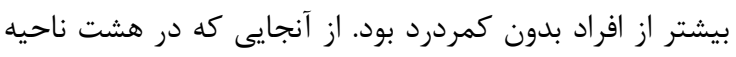

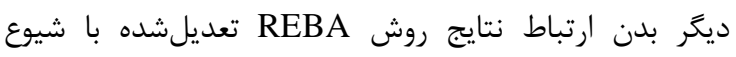

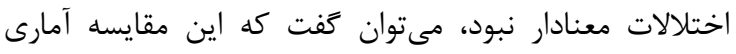

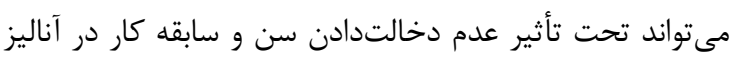

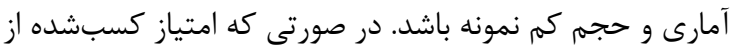

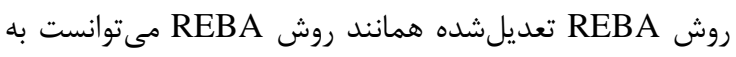

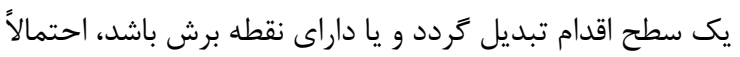

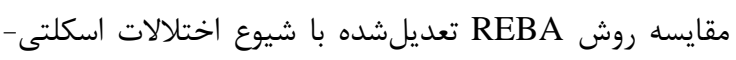

عضلانى مىتوانست نتايج متفاوتى را به همراه داشته باشند

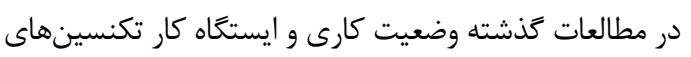

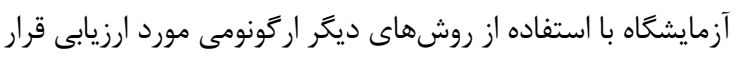

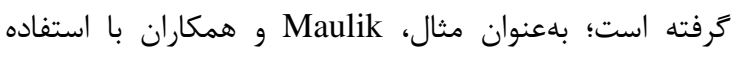

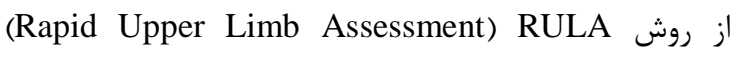

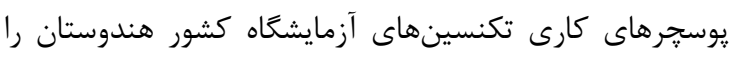

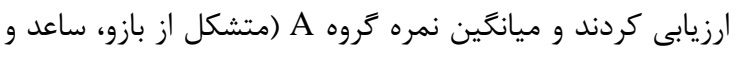

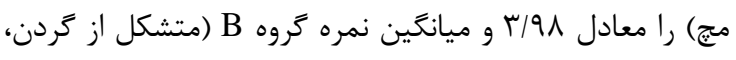

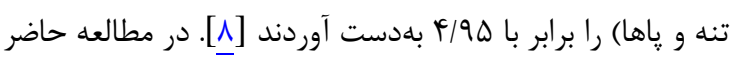

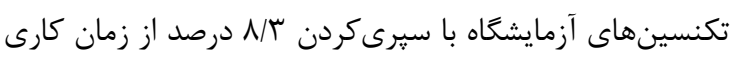

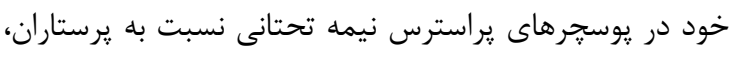

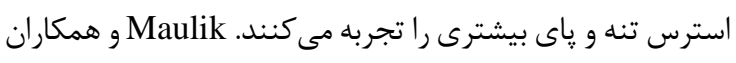

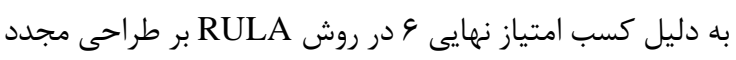

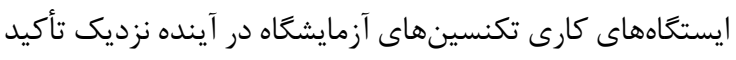

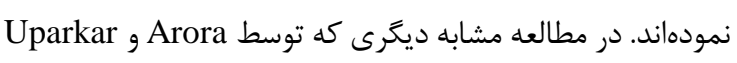

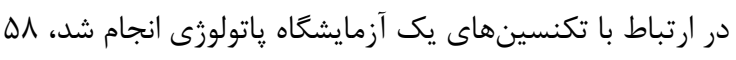

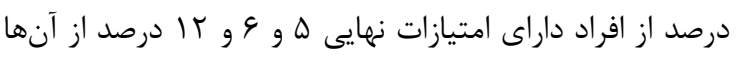

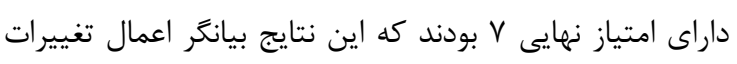

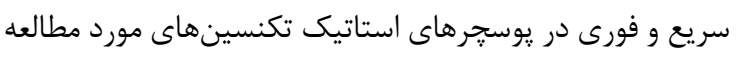

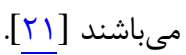
در مطالعات انجامشده در داخل كشور شرايط كار يرستاران
محاسبه كَرديد كه اين مههم از مزاياى اين روش به شمار مىرود؛

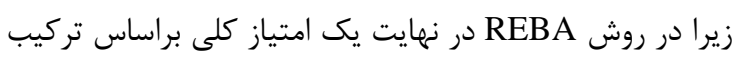

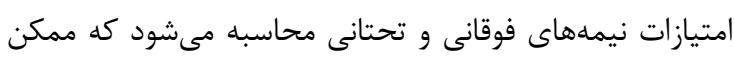

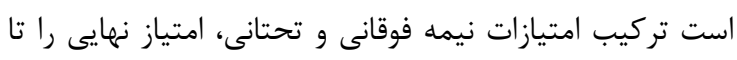

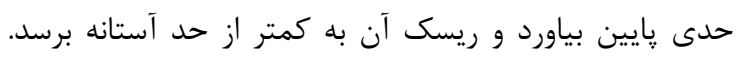

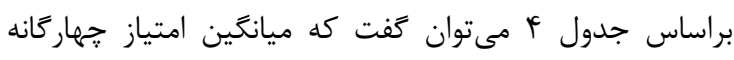

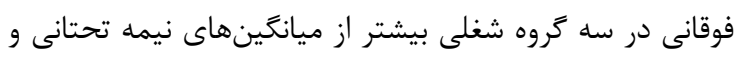

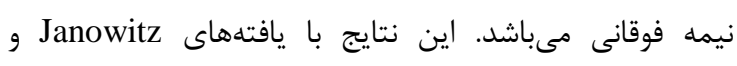

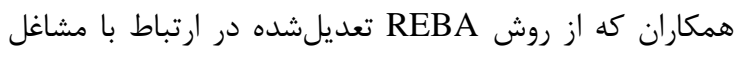

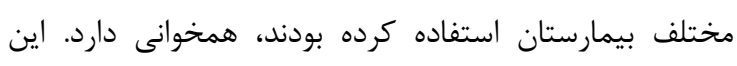

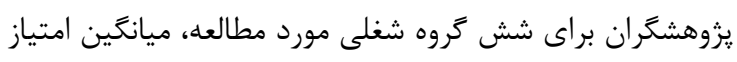

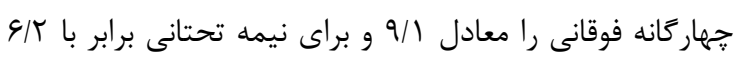

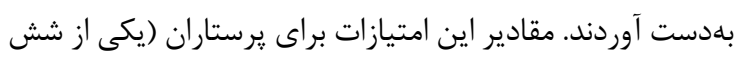

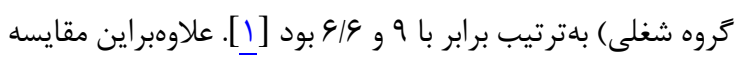

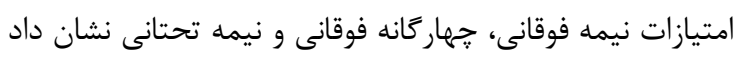

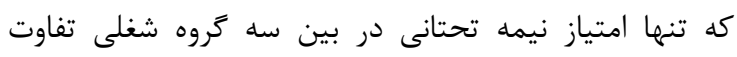

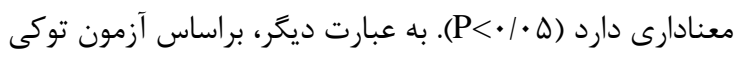

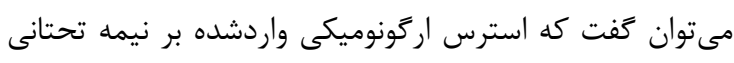

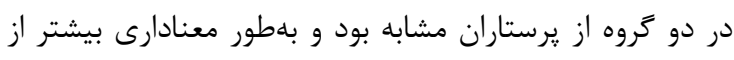

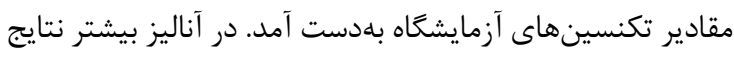

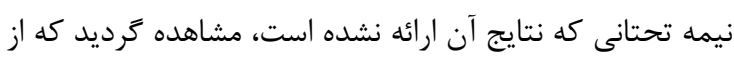

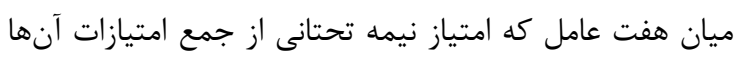

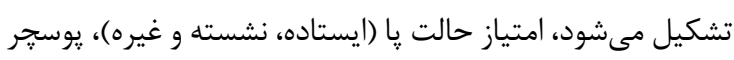

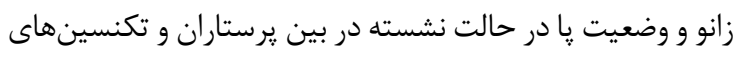

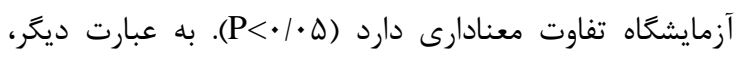

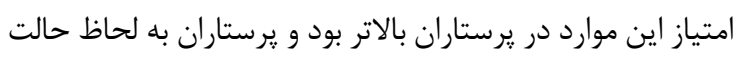

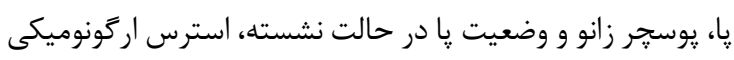

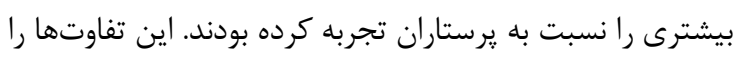

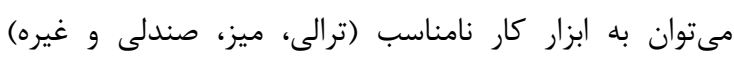

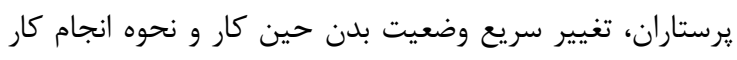

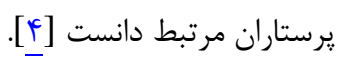

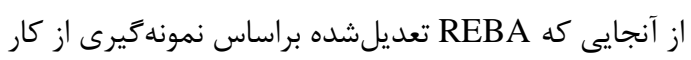

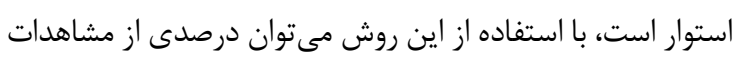

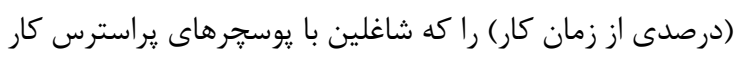

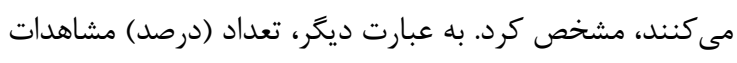

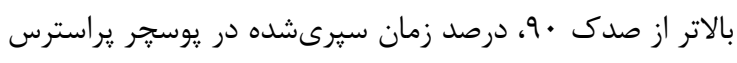

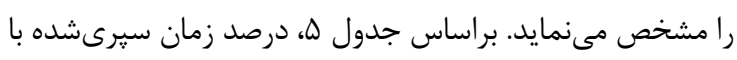

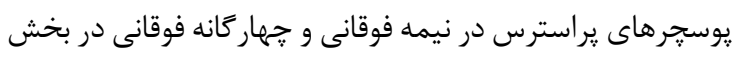

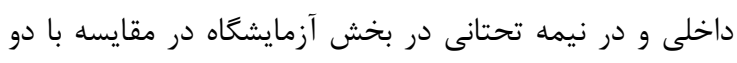

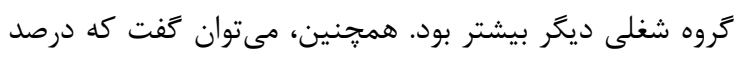

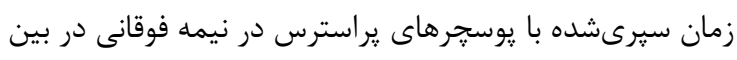

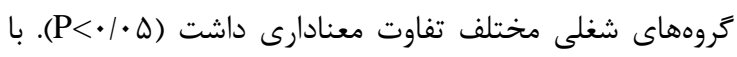

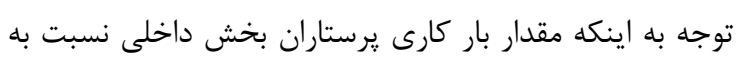

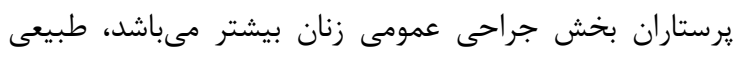


انجام مداخلات بلمنظور تصحيح يوسجرهاى تنه، يا، زانو و وضعيت يا مىتواند منجر به كاهش استرس بيومكانيكى در نيمه

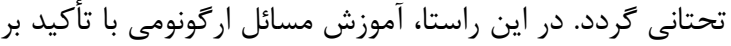

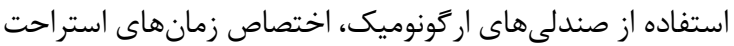

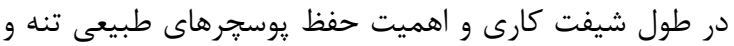

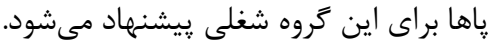

\section{نتيجه تيرى}

برستاران و تكنسينهاى آزمايشخاه مورد مطالعه، دردهاى

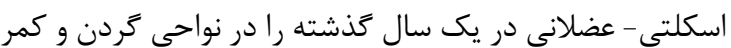

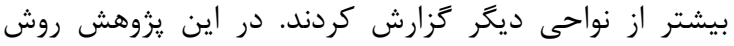

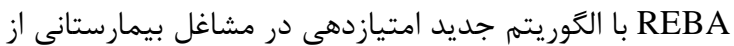
قبيل يرستاران و تكنسينهاى آزمايشگاه به راحتى اجرا كرديد.

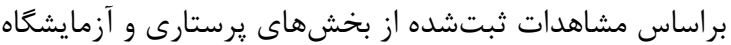
تشخيص طبى بيمارستان مورد مطالعه، يوسجرهاى يراسترس برس برس

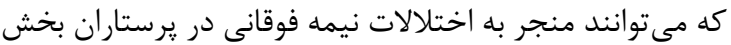

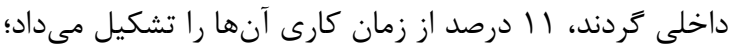

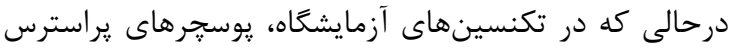

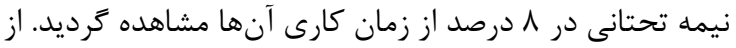

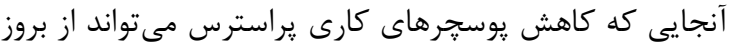
اختلالات اسكلتى - عضلانى يرستاران و تكنسينهائ هاى آزمايشكاه

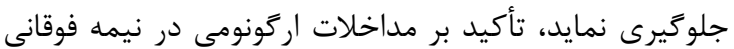

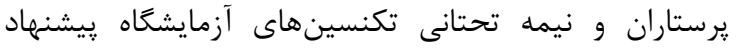

\section{تشكر و قدردانى}

اين مقاله بركرفته از پايانامهاه نويسنده اول مقاله بوده و با

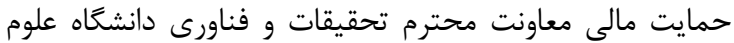

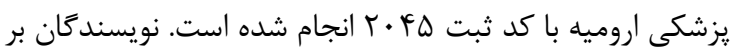

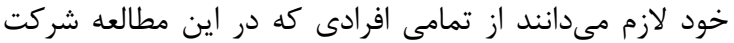

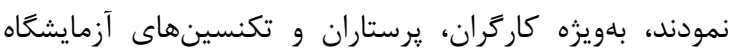
بيمارستان محل انجام يزوهش تشكر و قدردانى نمايند.

\section{REFERENCES}

1. Janowitz IL, Gillen M, Ryan G, Rempel D, Trupin L, Swig $\mathrm{L}$, et al. Measuring the physical demands of work in hospital settings: design and implementation of an ergonomics assessment. Appl Ergon. 2006;37(5):641-58. PMID: 16226213 DOI: 10.1016/j.apergo.2005.08.004

2. Yasobant S, Rajkumar P. Health of the healthcare professionals: a risk assessment study on work-related musculoskeletal disorders in a tertiary hospital, Chennai, India. Int J Med Public Health. 2015;5(2):189-95. DOI: 10.4103/2230-8598.153836

3. Samaei SE, Mostafaee M, Jafarpoor H, Hosseinabadi MB. Effects of patient-handling and individual factors on the prevalence of low back pain among nursing personnel. Work. 2017;56(4):551-61. PMID: 28409765 DOI: 10.3233/WOR$\underline{172526}$

4. Tinubu BM, Mbada CE, Oyeyemi AL, Fabunmi AA. Work-related musculoskeletal disorders among nurses in Ibadan, South-west Nigeria: a cross-sectional survey. BMC Musculoskelet Disord. 2010;11(1):12. PMID: 20089139
به لحاظ ارگونومى فيزيكى مورد بررسى قرار گرفته است. در يزوهشى كه توسط عزيزيور و همكاران انجام شد، شرايط كار

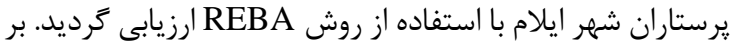

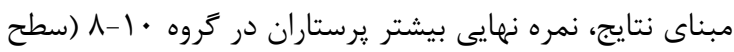

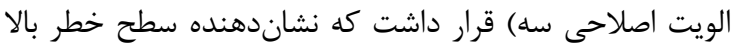

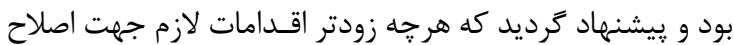
وضـعيت كارى يرستاران صورت گيرد [بr]. زمانيان و همكاران

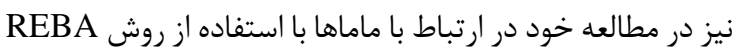

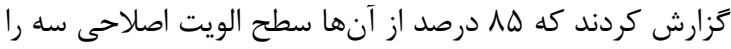

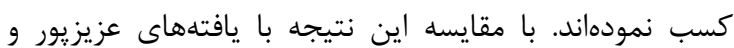

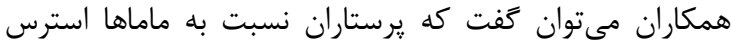
بيومكانيكى بيشترى را در كار خود تجربه مى كنند؛ از اين رو لازم

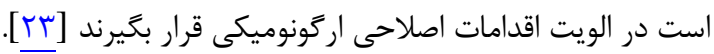
مطالعه حاضر محدوديتهايى نيز داشت كه مهمترين آن آن محدودبودن يزوهش به يك بيمارستان بود. درصورت انجام

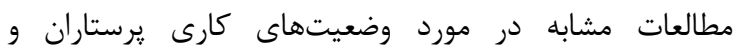

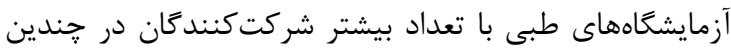

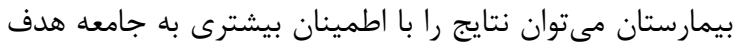

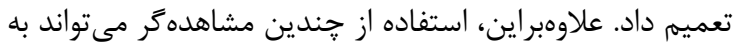
ثبت دقيقتر مشاهدات كمك كند؛ بنابراين استفاده از هُند

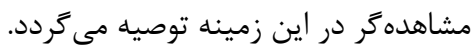
از سوى ديخر، بلمنظور كاهش ريسك ابتلا به اختلالات اسكلتى- عضلانى در جامعه مورد مطالعه لازم است اقدامات كنترلى جهت كاهش سطح عوامل خطر مورد توجه قرار گيرد؛ از

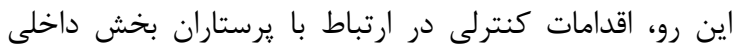

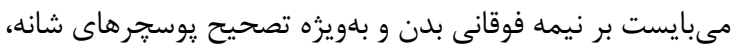

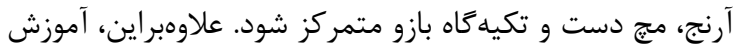

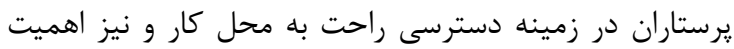

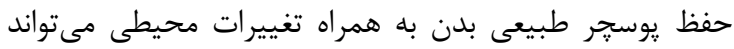

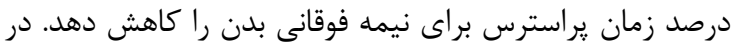

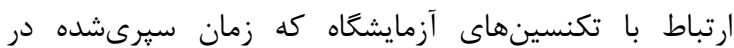
يوسجرهاى يراسترس نيمه تحتانى بدن در آنها بيشتر است،

DOI: $10.1186 / 1471-2474-11-12$

5. Karahan A, Kav S, Abbasoglu A, Dogan N. Low back pain: prevalence and associated risk factors among hospital staff. J Adv Nurs. 2009;65(3):516-24. PMID: 19222649 DOI: 10.1111/j.1365-2648.2008.04905.x

6. Smedley J, Inskip H, Trevelyan F, Buckle P, Cooper C, Coggon D. Risk factors for incident neck and shoulder pain in hospital nurses. Occup Environ Med. 2003;60(11):864-9. PMID: 14573717

7. Agrawal PR, Maiya AG, Kamath V, Kamath A. Work related musculoskeletal disorders among medical laboratory professionals: a narrative review. Int $J$ Res Med Sci. 2017;2(4):1262-6.

8. Maulik S, Iqbal R, De A, Chandra AM. Evaluation of the working posture and prevalence of musculoskeletal symptoms among medical laboratory technicians. $J$ Back Musculoskelet Rehabil. 2014;27(4):453-61. PMID: 24614833 DOI: 10.3233/BMR-140466

9. Barzideh M, Choobineh AR, Tabatabaee HR. Job stress 
dimensions and their relationship to musculoskeletal disorders in Iranian nurses. Work. 2014;47(4):423-9. PMID: 23324727 DOI: $10.3233 /$ WOR-121585

10. Mehrdad R, Dennerlein J, Haghighat M, Aminian O. Association between psychosocial factors and musculoskeletal symptoms among Iranian nurses. Am $J$ Ind Med. 2010;53(10):1032-9. PMID: 20568267 DOI: 10.1002/ajim. 20869

11. Khoshbakht M, Baghaie Lakeh M, Hasavari F, Blourchian M. Evaluation of body posture ergonomyic during work in intensive care units nurses in teaching hospitals of Guilan University of Medical Sciences in Rasht city in 2010. J Holist Nurs Midwifery. 2011;21(1):22-9. [Persian]

12. Zamanian Z, Salimian Z, Daneshmandi H, AliMohammadi Y. The REBA Technique ergonomic assessment of musculoskeletal disorders risk level among midwives of Shiraz State Hospitals. J Urmia Nurs Midwifery Facul. 2014;12(1):18-24. [Persian]

13. Askaripoor T, Kermani A, Jandaghi J, Farivar F. Survey of musculoskeletal disorders and ergonomic risk factors among dentists and providing control measures in Semnan. J Health. 2013;4(3):241-8. [Persian]

14. Abdollahzade F, Mohammadi F, Dianat I, Asghari E, Asghari-Jafarabadi M, Sokhanvar Z. Working posture and its predictors in hospital operating room nurses. Health Promot Perspect. 2016;6(1):17-22. PMID: 27123432 DOI: 10.15171/ hpp.2016.03

15. Carneiro P, Martins J, Torres M. Musculoskeletal disorder risk assessment in home care nurses. Work. 2015;51(4):65765. PMID: 26409938 DOI: 10.3233/WOR-152024

16. Shankar R, Kalappa S. Practice patterns and their influence on prevalence of musculoskeletal disorders among Indian dentists. Int J Res Med Sci. 2017;3(12):3459-64. DOI: 10.18203/2320-6012.ijrms20151229

17. Kim T, Roh H. Analysis of risk factors for work-related musculoskeletal disorders in radiological technologists. $J$ Phys Ther Sci. 2014;26(9):1423-8. PMID: 25276028 DOI: 10.1589/jpts.26.1423

18. Jones T, Kumar S. Comparison of ergonomic risk assessment output in four sawmill jobs. Int $J$ Occup Saf Ergon. 2010;16(1):105-11. PMID: 20331923 DOI: 10.1080/10803 548.2010.11076834

19. Sharifnia SH, Haghdoost AA, Hajihosseini F, Hojjati H. Relationship between the musculoskeletal disorders with the ergonomic factors in nurses. Koomesh. 2011;12(4):372-8. [Persian]

20. Aghanasab M, Ghalenoei M, Kouhnavard B, Ahmadi Panah $\mathrm{V}$. The relationship between musculoskeletal disorders and workstation conditions among academic and nonacademic staffs in school of public health, Qazvin University of Medical Sciences in 2012. J Health. 2017;8(1):35-44. [Persian]

21. Arora A, Uparkar SM. Ergonomic risk assessment in pathology laboratory technicians. Can J Med Technol. 2015;32:95-100.

22. Azizpour Y, Delpisheh A, Maghsoodi Moghadam R. Ergonomic evaluation of job performance within the staff of the nursing and the operating room by reba technique. $J$ Nur Midwifery Urmia Univ Med Sci. 2015;13(1):75-83. [Persian]

23. Zamanian Z, Honarbakhsh M, Jabari Z. Survey of muscle fatigue for using MFA method and determination of some risk factors musculoskeletal disorders among tailors in Shiraz, 2015. Iran Occup Health. 2017;14(1):47-56. [Persian] 